\title{
Computerized Visual Perception Games and its Effects on Learning Letters and Numbers among Jordanian Kindergarten Children
}

\author{
Ebtesam Qassim Rababah \\ Department of Curriculum and Teaching Methods \\ Yarmouk University, Jordan \\ Mais Nusair \\ Ministry of Education, Jordan \\ Ayed Hamdan AlHersh \\ Department of Curriculum and Teaching Methods \\ Yarmouk University, Jordan
}

\begin{abstract}
This study investigated the effect of computerized visual perception games on learning letters and numbers among Jordanian kindergarten children. A set of computerized visual perception games, as well as two tests for both Arabic letters and mathematics, were prepared to study the objective. The study was conducted on students in Tawasol Academy Kindergarten in Irbid Governorate, Jordan with a sample size of (50) students divided into experimental and control groups. Results showed that computerized visual perception games had an effect on improving visual perception, letters and numbers learning in these Kindergarten children. Results also showed significant $(p \leq 0.05)$ differences in numbers and letters learning among Kindergarten students between the control and experimental groups. (40\%) of this effect size for both letters and numbers is attributed to the impact of computerized visual perception games. Based on the results, parents of Kindergarten children should be made aware of the importance of computerized visual perception games in learning letters and numbers. Teachers should also learn the impact and effectiveness of using visual perception games in improving learning letters and numbers and the educational process in general.
\end{abstract}

Keywords: Computerized Games; Visual Perception; Kindergarten Children; Learning Letters and Numbers

\section{Introduction}

The pre-school stage is considered one of the most important stages in a child's life and the formation of his or her personality, as it gives the child an 
opportunity to gain experiences and knowledge (Aldridge \& Goldman, 2007; Rababah, 2012; Al Shammari \& Olaimat, 2019), to develop school readiness skills (Throndsen, Shumway, Moyer-Packenham, 2019), and acquisition of numeracy and literacy skills (Al Shammari \& Olaimat, 2019; Barham, Ihmeideh, Al-Falasi, Alabdallah, 2019). Therefore, it is necessary to pay attention to language experiences and the process of preparing children for reading by providing exposure to necessary skills, especially before they are introduced to the actual reading stage (Dickinson \& Tabors, 2001; Hashman, 2008; Mukdadi, Batiha, \& Martín, 2016; Rababah, 2017).

One of Jordan's modern issues, and one it is attaching intense attention to, is literacy and the process of preparing children for reading due to the positive effects it has on them, particularly in developing educational and cultural levels. Previous research has shown visual discrimination and letter and number recognition are important steps in helping children achieve high literacy and numeracy standards (Richmond, 2010). Other researchers have stated that visual perception disturbances can lead to a child falling into many other errors while learning literacy, including an inability to distinguish between similar letters, bad copying, writing letters and numbers backward, and the inability to distinguish between beginnings and endings of letters (Richmond, 2010; Mohamed, 2012). Cognition includes many processes in the brain, including classification and the ability to interpret external stimuli from the environment; cognition is one of the basic psychological processes that are part of forming general human perceptions about meanings related to these concepts (Adam, 2007).

The development of visual perception skills lasts from about two months to (12) years old. For a six-year-old child, developing visual perception skills includes developing the distinction between right and left, space and time, and distinguishing shapes, as well as developing and increasing the ability to preserve visual memory (Howard, 1991).

Regarding visual perception, Naughton (2001) defined it as the translation of perceptions in the form of symbols transmitted through the optic nerves to the brain. Suleiman (2003) defined it as adding meaning, significance, or interpretation to sensory visual stimuli. Ahmed (2006) defined it as organizing, interpreting and treating the external sensory visual stimuli that exist in the individual's visual field in the visual centers of the brain. Mohamed (2012) described it as a dynamic process based on integrating other senses. Thus, visual perception is defined here as the process that determines responses to visual stimuli so that an individual can perceive what is happening around them and understand the relationship between the perception and the body.

Visual perception is considered one of the most important processes that occur in a person's life (Erhardt \& Duckman, 2005; Richmond, 2010). This is especially the case in the first years of life, as the percentage of what a person learns from visual stimuli constitutes approximately $(80 \%)$ of all stimuli in the first few years (Al-Hassan, 2017). Visual perception is also a sensory skill that enables an 
individual to perceive the surrounding external environment (Al-Hassan, 2017). Visual perception functions to distinguish similarities and differences between stimuli in terms of image, clarity, color, size, shape, density, depth and position. How the individual perceives and understands these stimuli all depends on previous experiences.

A child's ability to distinguish and remember visually are two of the most important visual perception skills in preparation of reading (Sorter \& Kulp, 2003; Richmond, 2010), due to the need to distinguish between the forms of letters and the link between sound and shape. Moreover, visual remembering is considered extremely important in learning to read and requires the ability to stop a mental image in the brain for a sufficient period of time to link it with other similar images that were previously stored in memory. In the case of a child's insufficient experience in this field, the ability to preserve the meanings of abstract symbols indicating letters is low, which explains the common phenomenon of substitution and deletion during early attempts to learn to read (Bredekamp and Copple, 1997).

Play and the use of educational games could develop perception and visual discrimination skills. Since technological development has affected most areas of life, it has also led to a change in the concept of play in children and a qualitative shift in the nature and types of games played by children. This raises the possibility for educators and educational personnel to integrate education with technology to bridge the gap in childhood learning (McManis \& Gunnewig, 2012; Neumann \& Neumann, 2017).

Many past studies have investigated electronic teaching games. Most have focused on directing and employing electronic games towards enriching educational material for student learning (Alghazo, Alsawaie, Al-Awidi, 2010; AlNatour \& Hijazi, 2018), providing them with additional available resources and introducing an element of excitement and suspense during the presentation of educational material (Alghazo et al., 2010; Neumann \& Neumann, 2017; Neumann, 2018). In light of rapid technological development, understanding and utilizing electronic games has become an urgent necessity, whereas it was a form of social luxury in the past (Alghazo et al., 2010).

Several studies have previously touched on the relationship between electronic visual perception games, reading and writing development, and the acquisition of basic skills such as knowledge of numbers.

Rosas et al. (2003) explored the effects of educational video games on learning basic mathematics and reading comprehension. Their sample consisted of $(1,274)$ students of the first and second grades in Chile, who were divided into three groups: experimental, internal control, and external control. Students were evaluated on their acquisition of reading comprehension, spelling, mathematical skills, and their motivation to use video games. Teachers' expectations of change due to the use of video games, their technological transfer, and handling of classroom dynamics, were assessed through ad hoc tests and classroom 
observations. The results showed significant differences between the groups in Math, Reading Comprehension, and motivation in favor of the experimental video game group.

Furthermore, in order to enhance preschool counting skills, Alghazo et al. (2010) investigated the effect of computer technology on preschool children's counting skills in Al-Ain, United Arab Emirates. They recruited 48 preschool children to serve in either experimental or control groups. They found counting skills were improved in both groups, but the experimental group outperformed in all counting skills. Moreover, Mohammad (2012) conducted a study to improve regular writing and reading skills by conducting sessions of a proposed visual perception program. (28) Participants (22 students and 6 teachers) were chosen from the third-grade level in Giza, Egypt. A literacy and mental ability test were used, and the researcher developed and used a visual perception tool for written and reading dyslexia. The results indicated improvement in writing and reading skills in post-study tools (compared to pre-study tools) for both the control and experimental groups, but the experimental group outperformed the control.

Abdullah (2013) conducted a study based on computerized educational games to improve the visual perception of autistic children. The sample of the study consisted of (30) children with autism ranging between $(8-12)$ years old. The experiment was conducted inside a group of artistic and national museums, following an experimental and descriptive approach. The results indicated a noticeable improvement in the visual perception of autistic children as a result of using computerized educational games.

Al-Salami (2014) studied the effects of using multimedia software on developing reading skills for third-grade students. The sample consisted of (40) thirdgraders from a school in Mecca, Saudi Arabia. The study sample was randomly divided into experimental and control groups of (20) students in each group. A multimedia-based program was employed in the experimental group, while the conventional reading method was used in the control group. For data collection, pre and post-tests were used. The results showed multimedia increased the ability of these students to read compared to traditional methods. Students in the experimental group also felt the multimedia method fit their learning style better than the traditional reading method.

Islam, Islam, Ahmad, and Shamsuddin (2014) developed two interactive digital learning materials for kindergarten children in Bangladesh, in addition to developing an interactive program aimed at teaching numbers $(0-10)$ in Bengali. Several applications and multimedia programs were used to develop these educational materials. The sample was chosen from a kindergarten school in the Dhaka area, and a total of (52) children aged between (4-5) years were chosen. A pre and post-test were performed by the assistant teachers of the class. The results showed that digital educational materials had a positive and noticeable effect on improving number-learning skills among these kindergarten children, as they showed marked improvement in learning and adaptation skills. 
Kamran (2015) also conducted a study aimed at revealing the effect of a tactilekinetic games approach to the development of some elements of kinetic intelligence and visual perception skills among pre-school children. The study also aimed at revealing post-test differences between the experimental group and the control in children ages (5-6) years. The research participants consisted of (30) kindergarten children in the Koya district of Iraq, where the sample included boys and girls. The sample was randomly divided by lottery into two equal groups, one experimental and the other control. The research tool was represented by tests of motor intelligence, and a measure of the growth of visual perception skills in these preschool children. The sense-kinetic games achieved excellence in the elements of motor intelligence and a scale of growth of visual perception skills among the children of the experimental group. The researcher found the children of the experimental group outperformed the children of the experimental group in the post-tests of some elements of motor intelligence and the development of visual perception skills.

The study conducted by Al-Hassan (2017) in Ajloun, Jordan aimed to reveal the impact of the use and application of a training program designed to develop the skill of visual perception and measure its impact on improving reading among students with learning difficulties. The sample of the study included (20) students with learning difficulties and was divided equally into control and experimental groups. Two tests were used to collect data (reading achievement and visual perception tests) in addition to using a therapeutic training program to distinguish visual perception skills applied for two months. The results showed statistically significant differences between the control and experimental groups in favor of the experimental group.

Neumann and Neumann (2017) conducted a study looking at the importance of using touch tablets to develop writing and reading skills in children during home and pre-school stages. The research dealt with three theoretical aspects: the first aspect involved theories in the field of using computers and literacy. The second aspect related to the importance of using tablets (touch screen) in pre-school and the third aspect looked at the use of touch screen tablets at home.

Neumann (2018) followed by investigating the effect of using tablet applications on enhancing writing and reading skills in young children. The sample included (48) children between (2-5) years old, divided evenly into a control group and an experimental group that used iPads (iPad) for (9) weeks at a rate of (30) minutes per week. During this period, three letters of the alphabet (each week) were used, with (3) different applications such as letter tracking, letter matching, and drawing. The results showed a noticeable improvement in reading skills but not writing. The experimental group had increased knowledge of the names of letters, improvement in writing skills, and sound knowledge of concepts compared to children in the control group. These results did not confirm the ability of tablets to develop and teach writing to young children since it did not reach the level of significance for differences from the control group. 
In conclusion, most of the previously discussed studies conducted pre and posttests to analyze the effect of technology-based educational game programs. While the samples in the literature have differed, the results have been mostly positive for electronic teaching games. However, the limited literature on emergent literacy, and use of technology to facilitate it, suggests that more needs to be known about the effect of computerized visual perception games on emergent literacy (Neumann \& Neumann, 2017; Neumann, 2018) and pre-math skills. No Jordanian study on employing computerized visual perception games in learning the skills of reading and numeracy like learning numbers and letters skills were known to the authors at the time of conducting the study. Therefore, the purpose of this study was to identify the role of computerized visual perception games in learning letters and numbers for kindergarten children in Jordan, specifically.

\subsection{Research Problem and Questions}

Past research indicates that many children who have problems learning to read in their elementary years may be connected with poor development of prereading skills, which are skills that are usually acquired during pre-school years (August \& Shanahan,

2006). Snow and Matthews (2016) stated, "Children who don't develop ageappropriate literacy skills by the end of third grade are at high risk of school failure" (p. 58). Only 17\% of Jordanian children were found to be able to read the full text at the end of third grade, according to the National Survey included in the Early Grade Reading Assessment (EGRA), which was conducted by the United States Agency for International Development (USAID) in partnership with the Ministry of Education of Jordan (RTI International, 2013).

After reviewing the previous studies, and in light of the study by Islam et al. (2014), which confirmed that the use of computerized games enriches students' learning resources, the education of children needs to be supported using more interactive methods based on the use of technology to prepare an interactive environment with a variety of resources. Also, the lack of local studies reveals the need to assess the role of computerized games in enriching the basic skills of kindergarten students in Jordan. Additionally, since the second researcher has been a kindergarten teacher for years, it has become clear that most children at this stage now have tablets that enable them to use electronic games easily and at any time. Although these children own tablets equipped with multiple games, and use them continuously, utilizing these tablets and games to enrich reading and writing skills has not been studied in Jordan (Neumann \& Neumann, 2017). Thus, the purpose of this study was to investigate the effect of computerized visual perception games on learning letters and numbers for Jordanian kindergarten children. Based on this purpose, the following three questions led the study:

Question 1: "What are the effects of computerized visual perception games on learning letters and numbers and visual perception for Jordanian kindergarten children?" 
Question 2: "Are there statistically significant differences $(p \leq 0.05)$ between the control and experimental groups due to the impact of computerized visual perception games on Jordanian kindergarten students learning letters?"

Question 3: "Are there statistically significant differences $(p \leq 0.05)$ between the control and experimental groups due to the impact of computerized visual perception games on Jordanian kindergarten students learning numbers?"

\subsection{The Significance of the Study}

This study has significance in several areas. First, it adds to the knowledge and information about the impact of computerized visual perception games on enhancing letter and number learning for kindergarten children. Second, it explores the possible benefits of services provided by computerized visual perception games in enhancing learning in children. It can also further educate kindergarten teachers about the importance of employing digital visual perception games in enhancing letter and number learning for kindergarten children. Furthermore, this study contributes valuable data and information to the literature on the field of teaching literacy and early numeracy. Overall, it may help open the way for researchers to conduct further research in Jordan on the role of electronic or computerized games.

\subsection{Research Hypotheses}

Based on the discussion above and this study's objective, the following hypotheses were identified to examine the effect of computerized visual perception games on Jordanian kindergarten children's ability to learn letters and numbers:

- Hypothesis 1: computerized visual perception games will have a positive significant impact on Jordanian kindergarten children learning letters.

- Hypothesis 2: computerized visual perception games will have a positive significant impact on Jordanian kindergarten children learning numbers.

Thus, the independent variables for this study were (teaching method) with two values; computerized visual perception games, which were utilized in the experimental group, and the conventional way in the control group. The dependent variables were the students' scores on pre and post-tests to determine the learning of letters and numbers and children's visual perception.

\subsection{Limitations and Delimitations of the Study}

This study was limited to the effect of computerized visual perception games on learning letters and numbers of Jordanian kindergarten children and cannot be generalized further. The results are limited by the tools used by the researchers for this study. Delimitations included time limits related to conducting the study to the academic year 2018/2019 and kindergarten students in Irbid Governorate. Targeting different participants or changing the treatment time or duration might yield different results. 


\subsection{Study Context}

Jordan is located in the Middle East. The high percentage of young citizens with very few natural resources creates many challenges to Jordan's government achieving the fundamental needs of this part of the population. Education is one of the most vital sectors of the government's attention and concern. Jordan is considered an innovator in its focus to promote preschool (kindergarten) in the Middle East (United Nations International Children's Emergency Fund UNICEF, 2009). Pre-school in Jordan consists of two grade levels: Kindergarten 1 (KG1) for 4-year-olds and Kindergarten 2 (KG2) for five-year-olds.

One of the kindergarten's aims in Jordan is to enhance the children's readiness to begin school and improve literacy and numeracy skills (UNICEF, 2009). All levels of school in Jordan are taught in the Arabic language. The children are expected to know the 28 Arabic letters and know the numbers from 1-20 at the end of kindergarten. The focus is on distinguishing, memorizing and writing letters and numbers. The Arabic language is considered relatively difficult to learn, as its letters have different shapes when connected to make words based on different rules. Some letters can have up to four different shapes, which puts many young students in a difficult position to learn and remember these letters (Rababah, 2017). Thus, developing their early visual perceptions of letters and numbers would provide additional assistance to their learning (Beja, 2003; Sorter \& Kulp, 2003; Richmond, 2010; Abdullah, 2013; Ihmeideh, 2013; Al-Hassan, 2017).

\section{Research Method and Procedures}

\subsection{Study design}

The present study used a quasi-experimental research design and entailed two variables. The independent variable was instruction, and it had two levels: instruction from computerized visual perception games or conventional instruction. The dependent variable was the participants' performance on the letters and numbers post-tests.

\subsection{Participants and setting}

Two intact kindergarten groups, of (25) students each, enrolled at Tawasol Academy Kindergarten in Irbid Governorate were selected by convenience. The sample consisted of (21) boys, and (29) girls (mean age before intervention $=61.2$ months; $\mathrm{SD}=2.18$ ). The two groups were randomly assigned as experimental and control groups. The experimental group used the computerized visual perception games to learn letters and numbers. The control group received conventional classroom instruction.

\subsection{Ethical Consideration}

Consent from children, children's parents, the general directorate of education in Irbid Jordan, and school staff (principals, and kindergarten teachers) were obtained to implement the study. 


\subsection{Instruments}

The researchers prepared and collected a set of computerized visual perception games, as well as prepared two tests for both letter and number subjects and visual perception tests. These tools were judged under the supervision of arbitrators, and the following are definitions of the study tools:

First: Achievement Test of Numbers in Mathematics: This test consists of (5) questions that measure the following skills: Remembering the numbers and distinguishing them, completing the missing number, the previous number, the subsequent number and linking the number to the next number.

Second: Achievement test of letters in the Arabic language: This test consists of (4) questions that measure skills such as remembering letters, distinguishing letters and distinguishing missing letters.

Third: The visual perception test: This test consists of (6) questions, each question is worth 5 points. The visual perception test was limited to the following skills: visual distinction, visual recall, visual impairment, and visual integration. These skills were chosen because they have a great relationship with remembering and distinguishing letters and numbers, and they are among the reading readiness skills of children (Beja, 2003).

Then, a group of computerized visual perception games was chosen. This consisted of several games, including the programs Cyber, Smart Games, and Tex Typing, which contained a set of games for numbers and letters, and a multiplechoice option to select the correct number or shape. The games were shown to the experimental group for two months at the rate of three hours per week. Also, the tools were presented to arbitrators to express their opinion about them before being used on the children. These programs aim to develop children's visual perception and develop their distinction of the forms and numbers they see.

\subsection{Validity and Reliability}

The validity and reliability of the tools were confirmed in several ways. First, the instruments were presented to a group of (6) arbitrators from the faculty that specialize in educational technology, psychology, child-rearing, statistics, and evaluation. They were asked to express opinions on the tools in terms of the accuracy and integrity of the language formulation, and to add, omit, or merge items as they saw appropriate. This process was repeated until consensus was reached. The achievement test of numbers in mathematics consisted of (5) questions. The achievement test of Arabic letters consisted of (4) questions that measured the following skills: letter-memorizing, distinguishing letters, distinguishing the missing character, and visual perception of the letters.

Construct validity was confirmed by applying the tools to a survey sample from outside the study sample, consisting of (20) students from the same study community, and the test was re-applied with a time difference of two weeks over the same sample. A two-week period is an appropriate period to re-apply 
the test. The stability test parameter (Re-test Test) was calculated as the value of the constant stability factor of the number measurement tool in mathematics was (0.88). The construct validity of the letter measurement tool in the Arabic language was (0.87), and the construct validity of the visual perception measurement tool was (0.84). These values are appropriate for these types of scales (Odeh, 2010).

The internal consistency coefficient also was verified through Cronbach's Alpha. The internal consistency of the number measurement tool in mathematics was (0.81). The internal consistency of the letter measurement tool in the Arabic language was (0.85), and the coefficient of reliability of the Visual Perception Measurement Tool was (0.83). These values are suitable for this type of scale (Odeh, 2010).

\subsection{Equivalence tests}

Both the experimental and control groups took letters and numbers pre-tests to find out if the two groups were homogenous in terms of their knowledge. The equivalence of the experimental and control group was verified by analyzing the results using the $(t)$ value of the independent samples.

Table (1) indicates these results. The control group for the letter learning pre-test obtained an average of (6.68) and a standard deviation of (4.24); the experimental group had an average of (8.32) and a standard deviation of (5.699). The $(t)$ value was (1.137), with a probability value (0.261) that is greater than the level of significance. In other words, the differences between groups were considered and not statistically significant and the two groups could be considered equivalent for the purpose of this study.

Table 1: Equivalence Tests

\begin{tabular}{clccccc}
\hline Dimension & \multicolumn{1}{c}{ Group } & N & Mean & $\begin{array}{c}\text { Std. } \\
\text { Deviation }\end{array}$ & T & Sig. \\
\hline Achievement Test of & experimental & 25 & 10.76 & 6.220 & 1.41 & 0.165 \\
Numbers* & Control & 25 & 8.68 & 3.966 & & \\
\hline Achievement test of letters in $^{*}$ experimental & 25 & 8.32 & 5.699 & 1.137 & 0.261 \\
Arabic language* & Control & 25 & 6.68 & 4.424 & & \\
\hline \multirow{2}{*}{ The visual perception test** } & experimental & 25 & 17.44 & 4.992 & 0,15 & .879 \\
& Control & 25 & 17.20 & 6.013 & & \\
\hline
\end{tabular}

*The score out of (20)

** The score out of 30

It is also clear from the data in Table (1) that there were no statistically significant differences at $(p=0.05)$ among the three different pre-test results between the two groups. Thus, the two groups' levels were equivalent before implementing the instructional program.

\subsection{Study Procedures}

The researchers did the following to achieve the purposes of the study:

- Collect and prepare appropriate tools for the study through reviewing previous relevant research and by searching the Internet for games that 
serve this study, provided that these games contain exercises related to Arabic numbers and letters.

- After checking the validity of the study tools, they were presented to a group of arbitrators, who reviewed and revised the study tools until they were finalized.

- After being presented to the arbitrators, the tool was applied to a pilot sample to ensure its stability.

- The study sample was chosen from KG2 students in an appropriate way to ensure its representation in the total study community.

- A test was built that included a set of questions that measured some of the children's visual perception skills.

- A paper test for numbers in mathematics and Arabic letters were distributed to students of the two divisions as a pre-test, and

- The test was repeated after two months of teaching programs as a posttest.

- After presenting these games to the experimental group, the students' results were recorded and compared with the conventional results.

\section{Findings and Discussions}

Results were found after implementing the semi-experimental study procedures, collecting data, and performing the descriptive and inferential statistical treatment. These results are presented according to the initial study questions.

The first question was: "What are the effects of computerized visual perception games on learning letters and numbers and visual perception for Jordanian kindergarten children?" To answer this question, the researchers calculated the means and standard deviations of the participants' performance on the letters and numbers post-tests. The results are shown in Table (2).

Table 2: Means and standard deviations of the participants' performance on the letters, numbers learning and visual perception pre and post-test

\begin{tabular}{|c|c|c|c|c|c|c|}
\hline \multirow[b]{2}{*}{ Test Dimension } & \multirow[b]{2}{*}{ Group } & \multirow[b]{2}{*}{$\mathbf{N}$} & \multicolumn{2}{|c|}{ Pre-test } & \multicolumn{2}{|c|}{ Post-test } \\
\hline & & & Mean & $\begin{array}{c}\text { Std. } \\
\text { Deviation }\end{array}$ & Mean & $\begin{array}{c}\text { Std. } \\
\text { Deviation }\end{array}$ \\
\hline \multirow{2}{*}{ Learning letters* } & Control & 25 & 6.68 & 4.424 & 10.28 & 3.974 \\
\hline & Experimental & 25 & 8.32 & 5.699 & 16.64 & 4.020 \\
\hline \multirow{2}{*}{ Learning numbers* } & Control & 25 & 8.68 & 3.966 & 11.92 & 3.774 \\
\hline & Experimental & 25 & 10.76 & 6.220 & 17.40 & 3.028 \\
\hline \multirow{2}{*}{$\begin{array}{l}\text { The visual } \\
\text { perception test** }\end{array}$} & Control & 25 & 17.20 & 6.013 & 21.30 & 3.891 \\
\hline & Experimental & 25 & 17.44 & 4.992 & 26.47 & 4.360 \\
\hline
\end{tabular}

*The score out of (20)

** The score out of 30

Table (2) and Figure (1) show that the mean score of the experimental group on the learning letters post-test (16.64) was higher than that of the control group (10.28). Regarding the participants' performance on learning numbers post-test, 
the mean score of the experimental group (17.40) was also higher than the mean score of the control group (11.92). This difference indicates that the group that used computerized visual perception games obtained a higher difference in the means for the numbers and letters learning test between the pre and post-tests. This could be a result of the increase of children's visual perception $(M=26.47)$, which is very important and affected the children learning letters and numbers (Beja, 2003; Sorter \& Kulp, 2003; Richmond, 2010; Abdullah, 2013; Ihmeideh, 2013; Al-Hassan, 2017).
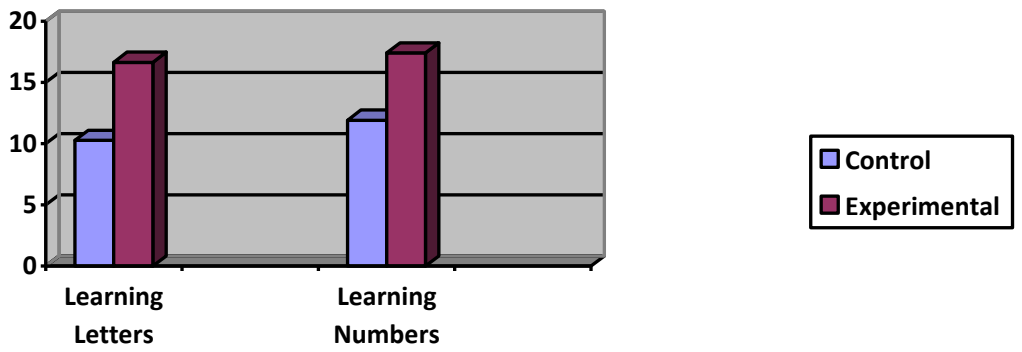

Figure 1: Means of the participants' performance on the letters and numbers learning post-test.

The results of the current study coincide with Mohamed (2012), which aimed to improve the skills of reading aloud and improving ordinary writing skills through the use of a tool to diagnose visual perception of students with learning difficulties in the first cycle of primary education. Also, these results were consistent with Abdullah (2013), which aimed to improve visual perception through educational games and indicated a marked improvement in the visual perception of the children as a result of the use of educational games.

These results also are consistent with Abdel-Al and Al-Najjar (2014), which aimed to reveal the impact of electronic educational games on developing and enhancing computer skills in kindergarten children. Their study also found a significant difference between the control group and the experimental group that used technology on pre and posttest measurements, with the experimental group showing greater improvement.

The second question was: "Are there statistically significant differences $(p \leq 0.05)$ between the control and experimental groups due to the impact of computerized visual perception games on kindergarten students learning letters?" To test question 2, the Independent Samples T-Test was performed and results are in Table (3):

Table 3: T-Test of the participants' performance on the letter learning post-test

\begin{tabular}{clllllll}
\hline Dimension & Group & N & Mean* $^{*}$ & Std. Deviation & T & Sig. \\
\hline $\begin{array}{c}\text { Achievement test of } \\
\text { letters in Arabic } \\
\text { language }\end{array}$ & Control & 25 & 10.28 & 3.974 & 48 & 5.626 & $001 .<$ \\
\hline
\end{tabular}

*the highest score is 20 
It is clear from the data of Table (3) that the mean of the experimental group reached (16.64) with a standard deviation of (4.020), which is higher than the mean for the control group of (10.28) with a standard deviation of (3.974). The difference was statistically significant, with the experimental group outperforming the control group.

To find the effect size of the learning method on the letter-learning post-test scores, the Eta squared was calculated. The computerized value of $P$ was (31.651) and the value of Eta (n2) was (39.7). This is a large impact size, with nearly (40\%) of the variance found in the post-tests attributable to the impact of the computerized visual perception games. This result is consistent with Al-Salami (2014), which analyzed the impact of using multimedia software on developing the reading skills for third-grade students and found that the ability of students to read in the experimental group compared to traditional methods was increased.

The current results also matched Rosas at al. (2003), who studied the effect of electronic games on numbers of mathematical and linguistic skills. They found that the groups with the electronic games outperformed the control groups. Moreover, the results were consistent with Neumann and Neumann (2017) and Neumann (2018) who found tablet applications enhanced pre-reading skills in young children.

The third question was: "Are there statistically significant differences $(p \leq 0.05)$ between the control and experimental groups due to the impact of computerized visual perception games on Jordanian kindergarten students learning numbers?" To answer this question, the Independent Samples T-Test was performed and the results are in Table (4).

Table 4: T-Test of the participants' performance on the numbers learning post-test

\begin{tabular}{lccclccc}
\hline Dimension & Group & N & Mean* & $\begin{array}{l}\text { Std. } \\
\text { Deviation }\end{array}$ & T & Sig. \\
\hline $\begin{array}{l}\text { Achievement } \\
\text { test of learning } \\
\text { the numbers }\end{array}$ & Control & 25 & 11.92 & 3.774 & 48 & 5.663 & $001 .<$ \\
\hline
\end{tabular}

*the highest score is 20

It is clear from the table (4) that the mean of the experimental group reached the value of (17.40), with a standard deviation of (3.028), which was considerably higher than the mean of the students 'marks for the control group of (11.92) with a standard deviation of (3.774). The result of the test $(F=5.663)$ reached the level of statistical significance.

The square Eta was calculated to find the effect size of this method on numberlearning scores. The effect was nearly identical to the result in question 2, with $(40 \%)$ of the variance between students attributable to the impact of the computer games. This may be related to what Alghazo et al. (2010), AlNatour and Hijazi (2018), and Saprudin, Liliasari, Setiawan, and Prihatmanto (2019) 
indicated about the many advantages of using computer-based activities such as audio and graphics, which made students interested, motivated, enjoyed, relaxed and engaged in the learning.

These results are consistent with Alghazo et al. (2010) and Islam et al. (2014), who developed two interactive educational materials for school children in a kindergarten in Bangladesh to enhance their numbers learning.

\section{Conclusion and Recommendations}

This study investigated the effect of using computerized visual perception games on learning letters and numbers and visual perception skills for Jordanian kindergarten children in the Irbid Educational Directorate. In order to achieve the study purpose, (50) kindergarten children were recruited and served in two sections (experimental and control group). The control group was taught by using conventional strategies, and the experimental group was taught by using computerized visual games. By comparing the performance of the experimental and control groups, the results showed computerized visual perception games had a significant effect on improving Jordanian kindergarten children's visual perception and ability to learn letters and numbers. It also showed significant (a $\leq 0.05$ ) differences in both number and letter learning among these kindergarten students, with the experimental groups significantly outperforming control group results.

In conclusion, the results of the current study were strongly in favor of the experimental computer game lessons over traditional methods, with the experimental groups scoring considerably higher on post-tests for both numbers and letters. The effect size was also high, at about (40\%) for both numbers and letters. These results are significant and important for kindergarten teachers to understand and implement. Findings educate kindergarten teachers about the importance of employing digital visual perception games in enhancing letter and number learning for kindergarten children. Teachers can be supported in this by holding training workshops to design and implement computerized visual perception games. Also, conducting and holding training courses for teachers at all stages of study on employing and using computerized visual perception games in the educational process and academic achievement is recommended.

Many implications abound from these findings. First, consider these strong results, along with similar results found in previous studies, further scientific research and studies are warranted to determine the impact of using computerized visual perception games in developing the learning of letters and numbers, and the educational process in general, for all levels of study.

\section{Disclosure statement}

The authors reported no potential conflicts of interest. 


\section{References}

Abdel-Al, A., \& Al-Najjar, M. (2014). The effectiveness of an electronic educational games program in developing computer skills for children in Riyadh. Educational Sciences Journal, 3(2), 639-676.

Abdullah, R. (2013). Program based on educational games to improve the visual perception of an autistic child. Arab Studies in Education and Psychology, 4(39), 227-249.

Adams, M. J., Foorman, B. R., Lundberg, I., \& Beeler, T. (1998). Phonemic awareness in young children: A classroom curriculum. Baltimore, MD: Brookes.

Ahmed, R. (2006). Optical perception diagnostic battery (Unpublished PhD thesis). Zagazig University, Egypt.

Aldridge, J., \& Goldman, R. (2007). Current issues and trends in education (2nd ed). Boston: Allyn and Bacon.

Al-Hassan, A. (2017). The effect of a training program to develop visual perception skills and measure its effectiveness in reading achievement for students with learning difficulties. Educational Sciences, 25, 175-209.

Alghazo, I., Alsawaie, O., \& Al-Awidi, H. (2010). Enhancing counting skills of preschoolers through the use of computer technology and manipulatives. The International Journal of Learning, 17(9), 159-176. https://doi.org/10.18848/14479494/cgp/v17i09/47227

AlNatour, A., \& Hijazi, D. (2018). The impact of using electronic games on teaching English vocabulary for kindergarten students. US-China Foreign Language, 16(4), 193-205. https://doi:10.17265/1539-8080/2018.04.001

Al-Salami, H. (2014). The effectiveness of multimedia on the third grade intermediate students' reading skills outcomes and on their attitudes toward reading (Unpublished Master Thesis). Umm Al-Qura University in Makkah Al-Mukarramah.

Al Shammari, K., \& Olaimat, H. (2019). The degree to which kindergarten teachers in the state of Kuwait practice language skills. An-Najah University Journal for Research, B: Humanities, 33(5), 877-906.

August, D., \& Shanahan, T. (2006). Developing literacy in second language learners: Report of the National Literacy Panel on minority language children and youth. Mahwah, NJ: Lawrence Erlbaum. https://doi.org/10.4324/9781315094922

Barham, A., Ihmeideh, F., Al-Falasi, M., \& Alabdallah, A. (2019). Assessment of firstgrade students' literacy and numeracy levels and the influence of key factors. International Journal of Learning, Teaching and Educational Research, 18(12). 174-195. https://doi.org/10.26803/ijlter.18.12.11

Beja, A. F. (2003). Teaching children reading and writing skills. Cairo: Dar Al Fikr.

Bredekamp, S., \& Copple, C. (1997). Developmentally appropriate practice in early childhood programs. (Revised Edition). National Association for the Education of Young Children, Washington, DC 20036-1426.

Dickinson, D. K., \& Tabors, P. O. (2001). (Eds.). Beginning literacy with language. Baltimore, MD: Paul H. Brookes.

Erhardt, R. P., \& Duckman, R. H. (2005). Visual-perceptual-motor dysfunction and its effects on eye-hand coordination and skill development. In M. Gentile (Ed.), Functional visual behaviour in children: An occupational therapy guide to evaluation and treatment options (pp. 171-228). Bethesda, Maryland: AOTA Press.

Hashman, A. N. (2008). Educational play and the extent of its impact on the psychosocial compatibility of a pre-school child (3-5 years) in Algiers: an educational psychological study (Unpublished doctoral thesis). Algeria University. 
Howard, E. (1991). A developmental assessment of visual perception for pre-school children (Doctoral dissertation). University of Nottingham, UK. http:/ / eprints.nottingham.ac.uk/13253/1/281004.pdf

Ihmeideh, F. (2013). Literacy development in early childhood. Amman, Jordan: Dar Alfiker.

Islam, B., Islam, K., Ahmed, A., \& Shamsuddin, A. K. (2014). Interactive digital learning materials for kindergarten students in Bangladesh. International Journal of Trends in Computer $\quad$ Science,
https://arxiv.org/ftp/arxiv/papers/1411/1411.2075.pd

Kamran, N. (2015). The impact of tactile-kinetic games approaches to the development of some elements of kinetic intelligence and visual perception skills among preschool children. Journal of Physical Education Sciences, 8(2), 168-192..

McManis, L. D., \& Gunnewig, S. B. (2012). Finding the education in educational technology with early learners. Young Children, 67(3), 14-24.

Mohamed, M. (2012). The impact of the training of visual perception on improving reading $\mathcal{E}$ writing skills of students with learning disabilities in the first stage of elementary education. Unpublished doctoral thesis, Institute of Educational Studies Department of Educational Psychology - Cairo.

Mukdadi, A. A., A Batiha, A., Martín, J. L. (2016). Improving the reading skills of Jordanian students with auditory discrimination problems. International journal of nursing studies 5(1), 51-55. http:/ / dx.doi.org/10.14419/ijans.v5i1.5444

Naughton, K. (2001). Linguistic description and analysis of verbs of visual perception in American Sign Language (ASL) (PhD thesis). The university of New Mexico, NM, USA.

Neumann, M., \& Neumann, D. (2017). The use of touch-screen tablets at home and preschool to foster emergent literacy. Journal of Early Childhood Literacy, 17(2), 203220. https://doi.org/10.1177\%2F1468798415619773

Neumann, M. (2018). Using tablets and apps to enhance emergent literacy skills in young children. Early Childhood Research Quarterly, 42, 239-246. https://doi.org/10.1016/j.ecresq.2017.10.006

Odeh, A. (2010). Evaluation and measurement in teaching process. Jordan: Al Amal Dar.

Rababah, E. (2012). Multiple case study: Developmentally appropriate beliefs and practice of United States and Jordanian kindergarten teachers (Doctoral dissertation). University of Alabama at Birmingham. ProQuest Thesis \& dissertations. UMI Number: 351230.

Rababah, E. (2017). The impact of using reading storybooks and writing journal activities on print and phonemic awareness of Jordanian kindergarten children. Journal of Educational and Psychological Studies, 11,736-748. http://dx.doi.org/10.24200/jeps.vol11iss4pp736-748

Richmond, J. E. (2010). School aged children: Visual perception and reversal recognition of letters and numbers separately and in context (PhD thesi). The Edith Cowan University. $\quad$ Retrived from https:/ / ro.ecu.edu.au/cgi/viewcontent.cgi?article=1128\&context=theses

Rosas, R., Nussbaum, M., Cumsille P., Marianov, V., Correa, M., Flores P., Grau V., Lagos, F., Lopez X., Lopez V., Rodriguez, V\& Salinas, M. (2003). Beyond nintendo: Design and assessment of educational video games for first and second grade students. Computers and Education, 40, 71-94.

Saprudin, S., Liliasari, L., Setiawan, A., \& Prihatmanto, A. (2019). The effectiveness of using digital game towards students' academic achievement in small and large classes: A comparative research. International Journal of Learning, Teaching and Educational Research, 18(12), 196-210. https://doi.org/10.26803/ijlter.18.12.12 
Snow, C. E., \& Matthews, T. J. (2016). Reading and language in the early grades. Future of Children, 26(1), 57-74. Retrieved from https://eric.ed.gov/contentdelivery/servlet/ERICServlet?accno=EJ1118540

Sorter, J. M., \& Kulp, M. T. (2003). Are the results of the Beery-Buktenica Developmental Test of Visual-Motor Integration and its subtests related to achievement test scores? Optometry and Vision Science, 80(11), 758-763. https://doi.org/10.1097/00006324-200311000-00013

Suleiman, A. (2003). Visual perception and learning difficulties. Cairo: Arab Thought House for Publishing and Distribution.

Throndsen, J., Shumway, J., \& Moyer-Packenham, P. (2019). The relationship between mathematical literacy at kindergarten entry and public preschool attendance, type, and quality. Early Childhood Education Journal. https://doi.org/10.1007/s10643-019-01014-7

UNICEF (2009). Jordanian initiative for developing ECE: Make Jordan worthy for children. UNICEF National Office for the Middle East and North Africa, Amman.

RTI International (2013). All children learning, early grade learning brief. JORDAN. Retrieved from: https://www.globalreadingnetwork.net/sites/default/files/eddata/ACL_Tech nical_Country_Brief_Jordan_FINAL_TO_USAID_11_18.pdf 